\title{
Aspectos orofaciais dos maus-tratos infantis e da negligência odontológica
}

\section{Orofacial aspects of childhood abuse and dental negligence}

Andreza Cristina de Lima Targino M assoni ${ }^{1}$

Ângela M aria Brito Ferreira ${ }^{1}$

Ana Karla Ramalho Aragão ${ }^{1}$

Valdenice Aparecida de $M$ enezes ${ }^{2}$

VivianeColares ${ }^{2}$

1 Pós-Graduação em Odontopediatria, Faculdade deOdontologia, Universidadede Pernambuco. Av. Genreal Newton Cavalcante 1650, Tabatinga. 54753-220 Camaragipe PE. andrezatargino@gmail.com

${ }^{2}$ Faculdade de O dontologia, Universidade de

Pernambuco.
Abstract The aim of this paper was to identify themain oral and dental aspects of childhood abuse and dental neglect, contributing to the identification of these victims in a dental office. A bibliographic research was carried out, in ADOLEC, M EDLINE, LILACS and BBO databases. Thefollowing key words were used: child abuse, oral manifestations, dentists; role; liability, legal. It was verified that violence against children happens in general at home and the resulting orofacial injuries encompass: injuries, burns and lacerations on soft and hard tissues, bite marks and gradually-healed wounds. It can have wounds in other parts of the body next to the oral cavity, such as periorbital wound and nasal injury. Regarding sexual abuse, many victims do not present any associated physic signs; therefore, behavioral indicators must be observed. The immediate recognition and report of childhood abuse and dental negligence by dental surgeon are essential for children protection. Therefore, it is critical to definemore effectiveaction from those professionals, by registration and denunciation of suspect cases to child protection agencies.

Key words Child abuse, Oral manifestations, Dentists, Role, Liability, Legal
Resumo 0 objetivo deste artigo foi identificar os principais aspectos orofaciais dos maus-tratos infantis e da negligência odontológica, contribuindo com a identificação destas vítimas no ambiente odontológico. Foi realizada uma pesquisa bibliográfica nas bases de dados Adolec, M ED LINE, LILACS e BBO. Utilizaram-se como descritores: maus-tratos infantis, manifestações bucais, odontólogos, papel (figurativo) eresponsabilidadelegal. Verificou-se que os maus-tratos infantis acontecem em geral em domicílio e os ferimentos orofaciais decorrentes incluem trauma, queimaduras e lacerações dos tecidos duros e moles, marcas de mordida e hematomas em vários estágios de cura. Pode haver ferimentos que envolvem outras partes do corpo próximas à cavidade bucal, como hematoma periorbital econtusão nasal. Q uanto ao abuso sexual, muitas vítimas não apresentam nenhum sinal físico associado; assim, indicadores comportamentais devem ser observados. A imediata identificação e o relato de maus-tratos infantis e da negligência odontológica pelo cirurgião-dentista são essenciais para a proteção das crianças, sendo fundamental uma maior atuação destes profi ssionais, através do registro e denúncia dos casos suspeitos às agências de proteção à criança.

Palavras-chave Maus-tratos infantis, $M$ anifestações bucais, 0 dontólogos, Papel (figurativo), Responsabilidadelegal 
Introdução

A infância é vista tradicionalmente como uma fase de divertimento etranquilidade, eo Estatuto da Criança e do Adolescente, de 13 de Julho de 1990, sob a Lei no 8.069, dispõe no seu artigo 5 , que "nenhuma criança ou adolescente será objeto de qual quer forma de negligência, discriminação, exploração, violência, crueldade e opressão, punido na forma da lei qualquer atentado, por ação ou omissão, aos seus direitos fundamentais" ${ }^{\prime \prime}$. Entretanto, para milhares de crianças, a violência ea negligência são partes da vida diária, enão ocorrem apenas nas ruas, mas também em seus próprios lares, em decorrência da ação de adultos que supostamente deveriam protegê las.

Assim, os maus-tratos infantis representam um problema crescente em todos os segmentos da sociedade ${ }^{2-4}$. Estes são entendidos como a negligência (abandono e o não-oferecimento de necessidades básicas) ou o abuso físico, emocional ou sexual ${ }^{5}$ de pais ou responsáveis junto à criança, que resulta em ferimento ou dano emocional significativo $0^{4,6-8}$.

No Brasil, os dados epidemiológicos sobre maus-tratos infantis apresentam-se deficientes, não existindo estatísticas nacionais fidedignas sobre o tema, mas apenas registros esparsos de serviços isolados ou de pesquisadores, que não traduzem a realidade atual, dificultando um maior enfrentamento do problema. Apesar da violência doméstica junto à criança ser frequente em nosso país, estima-se que apenas $20 \%$ das ocorrências sejam denunciadas, visto quea notificação dos casos a órgãos competentes é uma prática pouco exercida pelas pessoas 5.9 . Tsang e Sweet ${ }^{10}$ acrescentaram que os dados estatísticos sobre o abuso infantil são de difícil obtenção por este ser um comportamento "secreto".

Considera-se que existe abuso físico quando uma criança foi vítima de danos ou correu risco de danos por ser agredida com a mão ou outro objeto, ou ser chutada, sacudida, jogada, queimada, ou golpeada pelos responsáveis. 0 abuso emocional inclui atos que podem conduzir a desordens emocionais em longo prazo, como o isolamento social, a rejeição, a humilhação e as punições não físicas inadequadas (por exemplo, ser amarrado) 5,6,11. Já o abuso sexual envolve toda a exploração sexual (não consensual ou consensual) junto à criança ${ }^{2,6}$. Enquanto a negligência refere-se ao prejuízo ou risco como resultado de formas inadequadas de nutrição, vestimenta, higienee supervisão ${ }^{5}$.
Alguns estudos demonstram que a maioria dos ferimentos decorrentes dos maus-tratos infantis envolvea região or ofacial: cabeça, face, boca epescoço 2,3,9,10,12,13; além disso, muitas vezes, aqueleindivíduo quesofreu agressão élevado a buscar o tratamento odontológico. Estes aspectos colocam o cirurgião-dentista em uma posição oportuna para identificar essas vítimas ${ }^{10,14,15}$.

No entanto, muitos destes profissionais não têm o hábito de denunciar ou registrar casos suspeitos de agressão infanti $12,7,8,15,16$. Entre as razões pelas quais os cirurgiões-dentistas não relatam 0 abuso de crianças, citam-se a falta da confiança no seu diagnóstico de maus-tratos, desconhecimento sobre o tema, medo de tratar com os pais ou de se envolver, recusa em acreditar que os pais são negligentes, medo de perder o pacientee falta de treinamento. Este último aspecto poderia aumentar em atécinco vezes a possi bilidade dereconhecer os sinais de agressão enegligência à criança pelos profissionais da odontologia ${ }^{2,15-18}$.

Diante do exposto, percebe-se que os maustratos e a negligência odontológica infantil são problemas para os quais todos os profissionais da odontologia deveriam está atentos.

\section{Objetivo}

0 objetivo deste estudo foi identificar os principais aspectos orofaciais dos maus-tratos infantis e da negligência odontológica, contribuindo com a identificação destas vítimas no ambiente odontológico.

\section{M etodologia}

Foi realizada uma pesquisa bibliográfica através da Biblioteca Virtual em Saúde (BVS), identificando-se artigos publicados nas revistas indexadas nas seguintes bases de dados: Adolec, BBO, LILACS EMEDLINE.

Deforma combinada utilizaram-secomo descritores maus-tratos infantis, manifestações bucais, odontólogos, papel (figurativo) e responsabilidade legal, tendo como limites recém-nascido (até 1 mês), lactente (1-23 meses), pré-escolar (2-5 anos), criança (6-12 anos) e adolescente (13-18 anos), considerando o intervalo de tempo de 25 anos (entre 1983 e 2008) e os idiomas português, inglês e espanhol. Foi utilizado também o Estatuto da Criança e do Adolescente, publicado pelo M inistério da Saúde ${ }^{1}$. 
Foram encontradas 140 publicações; destas, 24 se repetiam entre as bases de dados e 86 foram excluídas por sereferirem a idosos, por serem relatos de casos ou experiências e por se dirigirem a outros profissionais de forma mais específica (enfermeiros e médicos). Dessa forma, foram incluídas trinta publicações, além do Estatuto da Criança e do Adolescente ${ }^{1}$, anteriormente mencionado.

\section{Perfil do agressor e da criança}

Os maus-tratosinfantis acontecem em geral dentro de casa ${ }^{12,19}$ e segundo Tsang e Sweet ${ }^{10}$ e J ohnson ${ }^{11}$, independem da classe socioeconômica, nível de instrução, família, religião ecultura, sendo difícil identificar de forma fiel traços preditivos da personalidade ou experiências da vida do adulto que são associadas ao abuso da criança. Para Tsang e Sweet ${ }^{10} \mathrm{eN}$ ai doo ${ }^{19}$, o estresse em família, seja ele financeiro, por separação, doença, uso de drogas ou desemprego, pode contribuir para os maus-tratos.

Dubowitz e Bennett ${ }^{4}$, Johnson ${ }^{11}$ e Naidoo ${ }^{19}$ acrescentaram alguns perfis psicossociais observados em agressores denunciados que podem identificar possíveisfatores de risco; são eles: história de abuso/negligência quando criança; falta de suporte social/isolamento social; expectativas frustradas em relação à criança; paternidade/ maternidade muito jovem; comprometimento mental/depressão e reversão do papel pai-filho no relacionamento com a criança. Quanto ao parentesco ou ligação com a criança, os agressores são em sua maioria mãe ou pai, seguidos de companheiros da mãe, avôs e tios ${ }^{12,19}$.

Determinadas crianças apresentam estatisticamenterisco aumentado para maus-tratos, sendo em sua maioria até três ou quatro anos de idade, em que o choro e o grito incontroláveis tendem a ser um fator predisponente ${ }^{11,19}$; além disso, estas têm mais dificuldade de estabelecer de forma independente contatos sociais que poderiam protegê-las ${ }^{12}$. Estes últimos autores ainda associaram uma maior ocorrência de agressão à criança do gênero masculino, o que não foi corroborado por Jessee?2.

\section{Abuso físico}

Ferimentos orofaciais não-acidentais decorrentes do abuso físico incluem o trauma dos tecidos duros e moles, além de queimaduras, lacerações, fraturas, marcas de mordida (tópico observado separadamente) e os hematomas em vários estágios de cura ${ }^{3,19-22}$. É importante observar que a boca é frequentemente traumatizada nos casos do abuso infantil por causa de sua associação psicológica com a pessoa agredida ${ }^{20}$.

$M$ anifestações orofaciais do abuso físico incluem $^{2-4,8,10,18-22:}$

- Lábios: podem apresentar hematoma, lacerações, cicatrizes do trauma persistente, queimaduras causadas por alimento quente ou cigarros, equimose, arranhão ou cicatrizes nas comissuras, indicativos da utilização de mordaça;

. Boca: pode apresentar lacerações no freio labial ou lingual causadas por beijo, alimentação ou sexo oral forçados, os quais são sinais característicos de casos severos do abuso de criança. Q ueimaduras ou lacerações na gengiva, língua, palato ou assoalho da boca, causadas por alimento ou utensílios quentes são outras manifestações associadas;

- Dentes: fraturados, deslocados, com mobilidade ou avulsionados, raízes residuais múltiplas sem história plausível para esclarecer osferimentos;

- M axila ou mandíbula: sinais da fratura passada ou atual, côndilos, ramos, sínfise, bem como má-oclusão incomuns resultando de trauma anterior.

É importante estar atento a ferimentos que envolvem outras partes do corpo próximas à cavidade bucal. Tais ferimentos podem incluir hemorragia da retina, ptose e hematoma periorbital, contusões e fraturas nasal, e danos à membrana timpânica, com hematoma na orelha.

\section{M arcas de mordida}

M arcas de mordida de adulto em crianças são geralmente associadas a al guma forma de abuso físico ou sexual. Estas aparecem de várias formas, 0 que depende das circunstâncias nas quais são provocadas. Assim, as marcas de mordida muitas vezes caracterizadas como hematomas são de difícil diagnóstico diferencial, por estes estarem muito presente na infância², sendo a suspeita mais evidente quando a natureza do ferimento for inconsistente com o relato do responsável eda criança ${ }^{18}$.

Para a avaliação de uma marca de mordida, utiliza-se o teste padrão no qual características importantes são identificadas, como a forma da dentição, dos dentes e as características anatômicas específicas do suspeito ${ }^{18}$. 
A típica marca de mordida humana tem uma configuração oval ou circular de equimose, sendo que com o exame mais aproximado pode-se revelar o dente de forma individual e a forma do arco. Uma área de hemorragia característica a qual representa 0 ato de "sugar" ou de "empurrar" a língua durante 0 ato de morder pode ocasionalmente ser encontrada entre as marcas de dentes ${ }^{2,23}$.

A avaliação do tamanho do arco pode ser útil em determinar se o agressor foi uma criança ou um adulto. Assim, se a largura de canino a canino for menor que três centímetros, a mordida provavelmentefoi de uma criança ${ }^{24}$. A aparência da marca de mordida muda enquanto o edema diminui eo tecido começa a se reparar; assim, as impressões dos dentes tornam-se mais visíveis após dois ou três dias da agressão?

Outro aspecto importante é distinguir entre mordidas humanas e de animais. As marcas de mordida humana são geralmente superficiais, se apresentando como hematomas ou abrasões. Por outro lado, as mordidas de animais resultam geralmentena penetração profunda, sendo acompanhadas por lacerações eatéavul sões dostecidos ${ }^{18,23}$.

As marcas de mordida, além de observadas, devem ser fotografadas, incluindo na fotografia uma régua milimetrada, a qual permitea realização do teste padrão da marca, possibilitando a comparação desta com as características da dentição do suspeito ${ }^{2,18}$.

É importante que os profissionais da odontologia tenham consciência de suas limitações a respeito do recol himento deevidências demarcas de mordida; assim sendo, o relato a um cirurgião-dentista forense pode ser importante para a documentação e a preservação da evidência ${ }^{2,23}$.

\section{Abuso sexual}

M uitas vítimas do abuso sexual infantil não apre sentam nenhum sinal físico óbvio. Assim, indicadores comportamentais devem ser observados, como o comportamento sexual impróprio, a defesa por se sentir ameaçado pelo contato físico e até mesmo a história relatada²,23,25,26.

Quando presentes, são indicadores muito fortes de abuso sexual: eritemas, úlceras, vesículas com secreção purulenta ou pseudomembranosa e lesões condilomatosas nos lábios, língua, palato, face ou na faringe $e^{2,25}$, as quais estão associadas às patologias ou alterações abaixo $0^{2,23-25,27}$ :

. Gonorréia: a mais frequente doença sexualmente transmissível entre as crianças que sofre ram abuso sexual. Pode aparecer sintomatologicamente nos lábios, na língua, no palato, na face e, em especial, na faringe, variando de eritema à ulceração e de lesões vesículo- pustular a pseudomembranosas. Um positivo da cultura para gonorréia em uma criança indica geralmente abuso;

- Condiloma acuminado: causado pelo papilomavírus humano (HPV), éuma lesão única ou múltipla, pedunculada, com aspecto de couve-flor;

- Sífilis: pápulas nos lábios ou pele da região perioral. Porém, é raramente encontrada em crianças; um positivo do teste para o pallidum treponema sugere fortemente 0 abuso sexual;

. Eritema e petéquias: quando presentes na junção dos palatos duro e mole ou assoalho da boca, podem ser sinais de sexo oral forçado.

\section{Negligência odontológica}

A negligência odontológica pode ser definida como a falha do pai ou responsável em procurar o tratamento para cárie visualmente não-tratada, infecções bucais e dor, ou a fal ha em seguir completamente com o tratamento uma vez informado das condições bucais e possibilidades de terapia viável ${ }^{28}$. Porém, questiona-se: a cárie dentária não-tratada indica sempre negligência odontológica? Diagnosticar a negligência odontológica em alguns casos torna-se difícil, visto que obstácul os como os financeiros, intelectuais e sociais devem ser considerados antes que a decisão de denunciar seja tomada². A dificuldade dos pais em pagar pela terapia adequada e por considerar a cárie dentária como inerente à vida de qualquer pessoa são al gumas razões para evitar o tratamento odontológico apropriado ${ }^{10}$.

Baseado na suposição de que certas patologias bucais são facilmente identificadas por pessoas leigas, têm-se os seguintes indicadores para a negligência odontológica: cárie rampante nãotratada, sintomatologia dolorosa sem buscar tratamento, infecção, sangramento ou trauma afetando a região orofacial e falta da continuidade do tratamento da patologia identificada ${ }^{2,10}$.

Em síntese, quando a patologia bucal foi diagnosticada, o tratamento necessário foi explicado e compreendido, e os obstáculos financeiros e de transporte foram eliminados, a ineficiência de um pai em buscar ou manter o tratamento se constitui negligência ${ }^{29}$. 0 que deve ser definido com cautela, considerando-se sempre as circunstâncias que levaram à omissão dos responsáveis. 


\section{Diagnóstico}

Embora muitos ferimentos não sejam causados pelos maus-tratos, o cirurgião-dentista devesuspeitar dos ferimentos traumáticos, observando sempre o relacionamento "responsável-criança", bem como mudanças no comportamento da criança. Um pai podetrazer uma criança ao dentista para tratar de dentes com mobilidade ou fraturados, mas podenão procurar um médico para o tratamento de outros tipos de ferimentos $5^{3,10,21,25}$.

Gerbert et al. ${ }^{30}$ sugerem que, quando da abordagem de vítimas de agressão, as questões devem ser incluídas com naturalidade em meio às questões do prontuário, para reduzir o desconforto da situação para o profissional e para o seu paciente.

Uma característica importante para o diagnóstico do abuso e da negligência infantil éa discrepância entre os achados clínicos e a história relatada pelo responsável e pela criança. Assim, quando possível, a criança deve ser questionada separada dos pais, e posteriormente estes devem ser questionados $23,25,26$.

Quando possível, éimportante que o registro inclua o período no qual o abuso aconteceu, se ocorreu mais de uma vez e o número devezes. As crianças mais novas muitas vezes não conseguem recordar uma data ou um mês específico. Dessa forma, uma linha detempo contextualizada à vida da criança pode ser criada, como, por exemplo, o seu aniversário, um feriado ou as férias ${ }^{26}$.

Também é relevanteidentificar o instrumento ou mecanismo de injúria, os quais foram citados por $\mathrm{Naidoo}^{19}$ e pela American Academy of Pediatrics Committeon Child Abuseand $\mathrm{N}$ eglect ${ }^{23}$ : mãos, pés, madeira, cano, vara, fio elétrico, frasco quebrado, garrafa, garfo, mamadeiras, líquidos quentes, cigarro, pedras e sapatos.

Os comportamentos da criança e do responsável também devem ser observados. A maioria de pais que acompanham sua criança ferida ao consultório apresentam-se ansiosos e preocupados sobre a situação da criança. Por outro lado, os pais agressores parecem frequentemente retraídos e as crianças indiferentes quando separadas dos pais, ou ainda agressivas, com desconforto ao contato físico e olhar vigilante?.

\section{Registro deinformações}

A documentação apropriada da criança fisicamente agredida ou negligenciada inclui a descrição do ferimento, fotografias e radiografias das estruturas envolvidas, sempre que possível. Bem como o registro da circunstância relatada pelo responsável, bem como pelo paciente. Também deve ser registrado o mecanismo de agressão ${ }^{26}$. As informações devem ser anexadas ao prontuário odontológico, incluindo aspectos sobre a posição, aparência, severidade e distribuição dos ferimentos ${ }^{10}$.

Em seguida, um formulário para registro de informações relacionadas às manifestações orofaciais dos maus-tratos infantis, adaptado do estudo de Cairns et al. ${ }^{12}$ (Quadro 1). 0 mesmo permite o registro dos ferimentos de forma categorizada, além da localização dos mesmos

\section{Relato de suspeitas}

Em caso de suspeita de maus-tratos contra a criança, deve-se comunicar ao Conselho Tutelar do município de moradia, o que pode ser verificado no artigo 13을 do Estatuto da Criança e do Adolescente: "Os casos de suspeita ou confirmação de maus-tratos contra a criança ou o adolescente serão obrigatoriamente comunicados ao Conselho Tutelar da respectiva localidade, sem prejuízo de outras providências legais"1. $\mathrm{Na}$ falta do Consel ho Tutelar, deve-se comunicar ao Juizado da Infância e da Juventude ${ }^{7,31}$.

Deixar de notificar o caso suspeito é considerado omissão e está sujeito à penalidade, como observado no artigo 245 do Estatuto da Criança e do Adolescente: Deixar o médico, professor ou responsável por estabelecimento de atenção à saúde e de ensino fundamental, pré escola ou creche, de comunicar a autoridade competente os casos de que tenha conhecimento, envolvendo suspeita ou confirmação de maus-tratos contra criança ou adolescente. Pena - multa de 3 a 20 salários dereferência, aplicando-se 0 dobro em caso de reincidência ${ }^{1}$.

Apesar das orientações propostas pelo Estatuto, entre os questionamentos levantados pelos cirurgiões-dentistas em relação à problemática do abuso infantil está a preocupação de os pais serem informados sobre a fonte do relato, visto quepodeser extremamentedifícil confrontar um pai com quem um relacionamento profissional foi estabelecido, além de expor o profissional ou a criança ao risco ${ }^{10}$. Assim, a estratégia de intervenção nos casos de abuso infantil deve ser direta e integrada facilmente à prática profissional do cirurgião-dentista, não devendo ameaçá-lo, nem ao seu paciente. É importante que as informações sejam transmitidas deforma sigilosa, sem que 0 agressor tome conhecimento ${ }^{8}$. 
Quadro 1. Formulário para registro de informações relacionadas às manifestações orofaciais dos maus-tratos infantis e negligência odontológica.

\begin{tabular}{|c|c|c|c|}
\hline \multirow{2}{*}{\begin{tabular}{|l} 
Data de nascimento \\
Sexo
\end{tabular}} & \multirow{2}{*}{$\frac{\text { Masculino ( ) }}{\operatorname{Sim}()}$} & \multicolumn{2}{|c|}{ Feminino ( ) } \\
\hline & & Não ( ) & \\
\hline Sinais de agressão orofacial? & $\begin{array}{l}\text { Lesão no olho } \\
\text { Hematoma } \\
\text { Abrasões } \\
\text { Lacerações } \\
\text { Queimaduras } \\
\text { M ordidas } \\
\text { Fraturas } \\
\text { Laceração no freio labial } \\
\text { Laceração no freio lingual } \\
\text { Trauma no palato } \\
\text { Trauma dental }\end{array}$ & 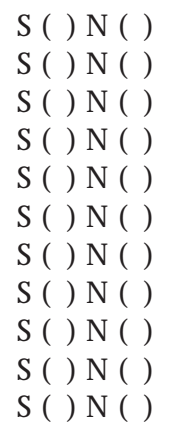 & $\begin{array}{l}\text { Cabeça ( ), Face ( ), Pescoço ( ) } \\
\text { Cabeça ( ), Face ( ), Pescoço ( ) } \\
\text { Cabeça ( ), Face ( ), Pescoço ( ) } \\
\text { Cabeça ( ), Face ( ), Pescoço ( ) } \\
\text { Cabeça ( ), Face ( ), Pescoço ( ) } \\
\text { Cabeça ( ), Face ( ), Pescoço ( ) }\end{array}$ \\
\hline \multicolumn{4}{|l|}{$\begin{array}{l}\text { M omento da injúria (Se relatou } \\
\text { e quem relatou) }\end{array}$} \\
\hline \multicolumn{4}{|l|}{$\begin{array}{l}\text { Local da injúria (Se relatou e quem } \\
\text { relatou) }\end{array}$} \\
\hline \multicolumn{4}{|l|}{$\begin{array}{l}\text { M ecanismo da injúria (Se relatou } \\
\text { e quem relatou) }\end{array}$} \\
\hline \multicolumn{4}{|l|}{$\begin{array}{l}\text { Alguma manifestação bucal } \\
\text { suspeita de abuso sexual? Qual? }\end{array}$} \\
\hline \multicolumn{4}{|l|}{$\begin{array}{l}\text { Impressões quanto à negligência } \\
\text { odontológica }\end{array}$} \\
\hline \multicolumn{4}{|l|}{$\begin{array}{l}\text { Registro/impressão da história } \\
\text { relatada pelo responsável }\end{array}$} \\
\hline \multicolumn{4}{|l|}{$\begin{array}{l}\text { Registro/impressão da história } \\
\text { relatada pela criança }\end{array}$} \\
\hline Detalhes e outras observações & & & \\
\hline
\end{tabular}

Fonte: adaptado deCairnset al. ${ }^{12}$.

Se existir dúvida a respeito de realizar uma denúncia ou não, consultar o médico do paciente, um assistente social, autoridades locais ou até um colega de profissão experiente neste assunto é recomendado. Além disso, é recomendado o contato com outras pessoas que têm ligação com a criança e que podem ter suspeitas similares e estejam dispostas a discuti-las ${ }^{10}$.

\section{Consideraçõesfinais}

A imediata identificação e relato de maus-tratos enegligência odontológica infantil pelo cirurgiãodentista são essenciais para a proteção das crianças. Assim, é fundamental uma maior atuação destes profissionais, através da observação, registro e denúncia dos casos suspeitos às agências de proteção à criança, para evitar que outras agressões tornem a ocorrer.

Sabe-se que a denúncia de maus-tratos não é fácil, mas assegurar a segurança da criança deve ser prioridade. Além disso, relatar significa contribuir e assumir a responsabilidade profissional inerente à profissão odontológica. 


\section{Colaboradores}

ACLT M assoni, AM B Ferreira, AKR Aragão participaram da concepção da proposta, coleta e análise de dados e redação final do artigo. VA $M$ enezes e $V$ Colares participaram da concepção da proposta e orientaram o desenvolvimento do artigo.

\section{Referências}

1. Brasil. Ministério da Saúde. Estatuto da Criança e do Adolescente. 1a ed. Brasília: Imprensa N acional; 1991.

2. Jessee SA. Physical manifestations of child abuse to the head, face and mouth: a hospital survey. ASDC J Dent Child 1995; 62:245-249.

3. Cavalcanti AL. Abuso infantil: protocolo de atendimento odontológico. Rev Bras Odontol 2001; 58(6):378-380.

4. Dubowitz $\mathrm{H}$, Bennett $\mathrm{S}$. Physical abuse and neglect of children. Child Care Health Dev 2007; 33(5):18911899.

5. Weber LND, Viezzer AP, Brandenburg OJ, Zocche CRE. Famílias que maltratam: uma tentativa de socialização pela violência. Psico-USF 2002; 7(2):163-173.

6. Province of British Columbia. Inter-ministry child abuse handbook. An integrated approach to child abuse and neglect. Victoria (BC): M inistry of Social Services and Housing; 1988.

7. Daruge $E$, Chaim LAF, Gonçalves RJ. Criança maltratada e a odontologia - Conduta, percepção e perspectivas - Uma visão crítica. Medcenter.com [site da Internet] [acessado 2007 dez 13]. Disponível em: http://www.odontologia.com.br/artigos_rel.asp ?id $=117$

8. Hendler TJ, Sutherland SE. Domestic Violence and its Relation to Dentistry: A Call for Change in Canadian Dental Practice. J Can Dent Assoc [periódico na Internet]. 2007 [acessado 2008 Jan 07]; 73(7):[cerca de 1 p.]. Disponível em: http:// www.cda-adc.ca/jcda/vol-73/issue-7/617.pdf

9. Cavalcanti AL, Duarte RC. M anifestações Bucais do Abuso Infantil em João Pessoa - Paraíba - Brasil. Rev Bras Ciênc Saúde 2003; 7(2):161-170.

10. Tsang A, Sweet D. Detecting Child Abuse and $\mathrm{Ne}$ glect - Are Dentists Doing Enough? J Can Dent Assoc 1999; 65:387-391.

11. Johnson CF. Child maltreatment 2002: Recognition, reporting and risk. Pediatrics Pediatr Int 2002; 44(5):554-560.

12. Cairns AM, M ok JYQ, Welbury RR. Injuries to the head, face, mouth and neck in physically abused children in a community setting. Int J Paediatr Dent 2005; 15:310-318.

13. Granville-Garcia AF, M enezes VA, Torres FB, Araujo JR, Silva PFR. O corrência de maus-tratos em crianças e adolescentes na cidade de Caruaru-PE. Pesqui Bras Odontopediatria Clin Integr 2006; 6(1):65-70.

14. Welbury RR, Hobson RS, Stephenson JJ, Jepson NJA. Evaluation of a computer-assisted learning programme on the oro-facial signs of child physical abuse (nonaccidental injury) by general dental practitioners. Br Dent J 2001; 190(12):668-670.

15. Andrade LK, Colares V, Cabral HM. Avaliação da conduta dos odontopediatras de Recife com relação ao abuso infantil. Rev Odonto Ciênc 2005; 20(49):231-236

16. Santos JF, Nunes KS, Cavalcanti AL, Silva EC. M austratos infantis: conhecimento e atitudes de odontopediatras de U berlândia e Araguari, M inas Gerais. Pesqui Bras Odontopediatria Clín Integr 2006; 6(3):273-293. 
17. Kassebaum DK, Dove SB, Cottone JA. Recognition and reporting of child abuse: a survey of dentists. Gen Dent 1991; 39:159-162.

18. Avon SL. Forensic Odontology: The Roles and Responsibilities of the Dentist. J Can Dent Assoc 2004; 70(7):453-458.

19. Naidoo S. A profile of the oro-facial injuries in child physical abuse at a children's hospital. Child Abuse N egl 2000; 24(4):521-534.

20. Needleman HL. Orofacial trauma in child abuse: types, prevalence, management, and the dental profession's involvement. Pediatr Dent 1986; 8(1):71-80.

21. Cavalcanti AL. Manifestações físicas do abuso infantil: aspectos de interesse odontológico. Rev Paul Odontol 2003; 25(5):16-19.

22. $M$ arques $C R$, Colares $V$. A identificação do abuso infantil pelo odontopediatra. J Bras Clin Odontol Integr 2003; 7(42):512-515.

23. American Academy of Pediatric. Committe on Child Abuse and Neglect. American Academy of Pediatric Dentistry. American Academy of Pediatric Dentistry Council on Clinical Affairs. Guideline on oral and dental aspects of child abuse and neglect. Pediatr Dent 2005-2006; 27:64-67.

24. American Academy of Pediatrics Committee on Adolescence: role of the pediatrician in management of sexually transmitted diseases in children and adolescents. Pediatrics 1987; 79:454-456.

25. Louzado M, Araújo CH, Scariot F, Dornelles M SO, Prado D. Manisfestaçöes orais em crianças abusadas sexualmente. Rev Bras Odontol 2001; 58(1):33-34.

26. Jackson AM, Rucker $A$, Hinds $T$, Wright JL. Let the Record Speak: Medicolegal Documentation in Cases of Child Maltreatment. Clin Ped Emerg M ed 2006; 7(3):181-185.

27. Syripinen S, Puronen M. Human papillomavirus infections in children: the potential role of maternal transmission. Crit Rev Oral Biol Med 2000; 11(2):259-274.

28. American Academy of Pediatric Dentistry. Committee on Child Abuse and N eglect. Recommendations of the Academy Board of Directors. American Academy of Pediatric: Elk Grove Village; 1984.

29. Loochtan RM, Bross DC, Domoto PK. Dental neglect in children: definition, legal aspects, and challenges. Pediatr Dent 1986; 8(1):113-116.

30. Gerbert B, M oe J, Caspers N, Salber P, Feldman M, Herzig K, Bronstone A. Simplifying physicians' response to domestic violence. West J Med 2000; 172(5):329-331.

31. Chaim LAF, Gonçalves RJ. A responsabilidade ética e legal do cirurgião-dentista em relação à criança maltratada. Rev ABO Nac 2006; 14(1):19-24.

Artigo apresentado em 10/06/2008

Aprovado em 14/10/2008

Versão final apresentada em 18/11/2008 